\title{
Research on Energy-Saving Design Method of Green Building Based on BIM Technology
}

\author{
Xiao-guang Zhao ${ }^{1}$ and Chun-Ping Gao $\mathbb{1}^{2}$ \\ ${ }^{1}$ Department of the Economics and Management, Hebei University of Environmental Engineering, Hebei 066102, China \\ ${ }^{2}$ Hebei Vocational \& Technical College of Building Materials, Hebei 066000, China \\ Correspondence should be addressed to Chun-Ping Gao; gaochunping11234@163.com
}

Received 30 November 2021; Revised 26 December 2021; Accepted 31 December 2021; Published 4 February 2022

Academic Editor: Tongguang $\mathrm{Ni}$

Copyright ( $) 2022$ Xiao-guang Zhao and Chun-Ping Gao. This is an open access article distributed under the Creative Commons Attribution License, which permits unrestricted use, distribution, and reproduction in any medium, provided the original work is properly cited.

\begin{abstract}
In view of the shortcomings of the traditional architectural design mode, such as high rework rate in the construction process and lack of collaborative design and intelligent information processing, a green building energy-saving design method based on BIM technology was proposed. Based on the comparative analysis of traditional computer-aided building design and BIM green building technology, the overall scheme of energy-saving design was constructed from the aspects of green building design principle, design preparation, and design concept. This paper expounded the connotation of energy-saving design elements from the aspects of modeling software selection, envelope energy-saving design, and lighting energy-saving design. Accordingly, the characteristics and process of building energy efficiency analysis based on BIM were proposed. Finally, the energy-saving effect evaluation method of green building based on BIM was given, and an example showed that the energy-saving design method of green building based on BIM proposed in this paper had good feasibility and effectiveness. The method proposed in this paper can provide a certain theoretical basis and application support for the application of BIM technology in the field of green building.
\end{abstract}

\section{Introduction}

Since the end of the last century, most developed countries have been deeply exploring green buildings and their applications and have successively issued some different evaluation standards based on the reality of various countries, which has accelerated the development of green buildings in the world to a great extent [1-3]. With the continuous development of green building field, BIM technology has been widely used in western developed countries. Relevant personnel in other countries have also conducted relevant in-depth research on BIM theoretical and technical system and its practical application and made great progress. Some scholars can realize the simulation of building energy-saving design and its effect by combining a three-dimensional building model with energy consumption analysis.

In recent years, with the promotion of BIM software, such as Revit series of Autodesk company and ArchiCAD of graph iSOFT company, it has been well applied in the field of green building $[4,5]$. Applying BIM technology to the design of construction projects can not only predict and find the deficiencies in the design but also avoid the additional consumption in the actual construction process [6-8]. For example, the effective integration of building a 3D model and structural model with the Revit structure can promote the information exchange and collaborative work of construction project participants.

The application of BIM technology is conducive to the completion of various design, construction, and later maintenance of construction projects, which not only promotes the renewal of architectural design methods but also improves work efficiency $[9,10]$. With the global energy crisis, energy shortage, and the continuous deterioration of the natural environment in recent years, how to use BIM technology to carry out energy-saving design of green buildings and scientifically evaluate the energy-saving effect has become a concern of relevant scholars. However, there 
are still some deficiencies in the application of BIM technology in green buildings, such as insufficient design accuracy and unscientific intelligent processing method. Therefore, how to improve green building design based on BIM technology is one of the urgent problems to be solved in the field of green buildings.

\section{Related Works}

Developed countries are the first to use BIM technology and have applied it to the whole process of construction projects. With the deepening of the concept of building energy conservation, the research and application of green building are also developing. Technology provides strong support for promoting the development of the construction field [11-13]. The adopted building information model can visually reproduce the real scene of the building and its stages from different dimensions, which fundamentally overcomes the shortcomings of the traditional building model. The core software of BIM can parameterize the building model and predict or simulate various situations that may occur in the building process through various information contained in the model. The collaborative operation between BIM building information model and other types of energysaving analysis software can scientifically evaluate the design effect of green buildings.

Using the traditional computer-aided design mode, due to the decentralized management of various departments and the inconvenient communication of information, it is difficult to realize the collaborative requirements of all parties in the construction project. The green building based on BIM technology not only maintains information interaction but also can use the collaborative work platform to carry out effective information interaction and integrated management for all personnel involved in the construction $[14,15]$. It provides important technical support for the collaborative development of the construction industry and other fields. The comparison between traditional computeraided building method and BIM green building technology is shown in Table 1.

The core of BIM can not only use BIM technology to optimize various architectural designs but also optimize the cooperation mode of partners in different stages of the construction process to effectively save the comprehensive cost of the building and reduce the energy consumption of the building. In addition, BIM technology is used to simulate building energy consumption. Based on the analysis of the simulation results, the building design scheme is continuously optimized, the best scheme is selected, and the resource utilization rate is also improved.

BIM technology has changed the design mode in the sense of traditional architecture. BIM building model can not only visualize space facilities but also extract relevant data and information by using the model, which is conducive to the design, construction, and maintenance of green building projects and can meet the communication and decision-making of construction projects by participants in different stages [16, 17]. In addition, the data platform provided by BIM can provide information support for effectively formulating various construction-related work plans such as construction cost plan, material use plan, and personnel scheduling plan to avoid risks, reduce costs, and improve efficiency during the implementation of construction projects.

The traditional architectural drawing cannot integrate information, and it is difficult to communicate during construction. Because the drawings and information of traditional building models are generally not related to each other, model modification is not only time-consuming but also prone to errors, which is difficult to provide substantive help for the construction industry building model that can predict the real situation after the completion of the building through information interaction, and BIM data center can provide various data for different stages and provide relevant services after the completion of the building. Participants in different stages of project implementation can update information synchronously without checking architectural design and construction drawings. As shown in Figure 1, the comparison results between the traditional building model and the BIM building model are shown.

\section{Overall Scheme of Energy-Saving Design}

3.1. Principles of Green Building Design. In the whole process of green building, energy-saving design not only is related to architectural features but also considers natural environmental factors and the relationship between the external environment and architectural features. Therefore, green building design needs certain principles.

(1) We should adhere to the principles of sustainable development and people-oriented. In order to meet the needs of long-term and stable development, green buildings should be able to coordinate the problems of sustainable development such as resource consumption, environmental pollution, and resource conservation. Because the building energysaving design is to better transform human living space, on the premise of ensuring that it does not affect the health of residents, the construction equipment and materials should be used reasonably when implementing green buildings.

(2) The energy-saving design of green buildings should comply with the comfort of living and the rationality of technology. When implementing green buildings, we should not only consider the spatial structure needs of residents for housing buildings but also make full use of the solar energy, wind energy, and other resource conditions provided by external nature according to the technical standards. Good energy-saving design can provide residents with good indoor temperature, humidity, and other environmental conditions.

(3) Based on the principle of saving resources and energy, the environmental differences in different regions should be considered in the energy-saving design of green buildings. Combined with the characteristics of external natural environment, 
TABLE 1: Comparison between traditional computer-aided architectural design and BIM green building technology.

\begin{tabular}{lcc}
\hline Item & Traditional architectural design & BIM green building technology \\
\hline Work cycle & Design phase & Entire cycle \\
Design dimension & Two-dimensional design & Space design above 3D \\
Working mode & Independent operation & Collaborative work \\
Design effect display & Plan drawing & Visual model \\
\hline
\end{tabular}

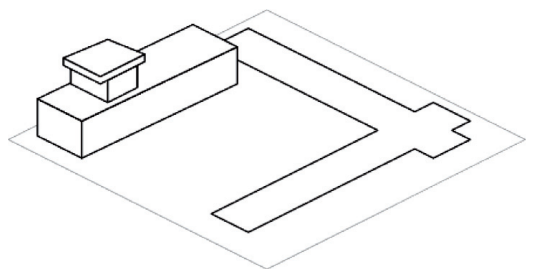

(a)
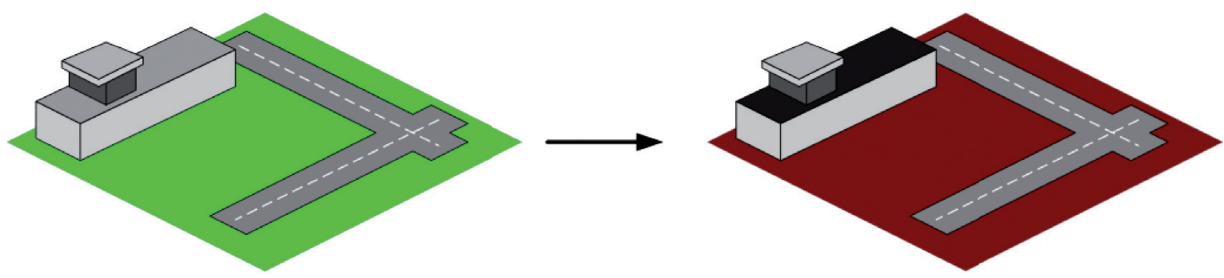

(b)

FIgURE 1: Comparison between traditional building model and BIM building model.

regional characteristics, and people's social life customs, green buildings should not only conform to the local construction style but also make full use of local resources and environment.

3.2. Preliminary Design Preparation. Since the effect of the energy-saving design is an important part of green building evaluation, whether energy is effectively saved and utilized is an important reference standard, and it is very important to promote the application of BIM in green buildings. In order to ensure the normal implementation of green buildings, the BIM model is generally used to analyze the natural light radiation and distribution outside the building, establish a feasible solar energy utilization scheme, and realize the full utilization of solar energy resources by green buildings.

At the same time, according to the analysis results of indoor natural lighting based on the BIM model, make full use of external lighting to reduce the energy consumption of indoor lighting. In addition, in the selection and use of energy-saving materials, according to the functional requirements of public buildings and the technical rationality requirements of architectural design, BIM technology should be used to detect the electromechanical pipe network to avoid some problems caused by the unreasonable design of electromechanical pipe network. Finally, in terms of indoor environment and structural thermal performance test, the parameters of peripheral structure and thermal function are used as the input parameters of the BIM building model, and the required parameters are calculated through relevant software to ensure that the green building can meet the national standards. If the design or implementation of the construction project does not meet the requirements of relevant national green building standards, it is necessary to reanalyze and calculate the building energy consumption.

3.3. Conceptual Design. In the energy-saving design of green buildings, it is usually transformed into a description that can be implemented according to the construction needs or ideas of residents. Therefore, the relevant design documents are the basis for the implementation of energy-saving of green buildings. When evaluating the results of green building, it is necessary to integrate the relevant building information in the design stage to obtain accurate and detailed energy-saving design information of green building and then import the relevant information into the BIM platform database to provide shared data for all participants in the implementation process [14].

The whole process of implementing green building requires cooperation and collaborative design in different professional fields, and the BIM model can provide a better information management platform for collaborative operation. Because the BIM model includes various detailed information about green building concept, it can provide a basis and support for the simulation and analysis of green building energy efficiency. In addition, the parameterization and modularization of the BIM model can provide accurate information feedback for the later energy-saving design effect. The specific implementation route of BIM-based green building energy efficiency design is shown in Figure 2. 


\section{Key Points of Energy-Saving Design}

4.1. Modeling Software Selection. Green building has been widely used with the development of BIM software technology. Choosing an appropriate BIM software is very important for green building energy-saving designers [18]. A building model is established by using BIM technology. On this basis, the energy conservation of green buildings is designed, the energy consumption is simulated and analyzed, and the technical route of building energy conservation simulation design is formulated according to the simulation analysis results.

In recent years, designers have mostly used Ecotec, Energy Plus, and other types of simulation analysis software to design green buildings and analyze the model simulation results, which has achieved good results. For example, Ecotec software has the characteristics of simple operation and specific analysis. It can optimize relevant parameters according to different architectural design models, providing an effective guarantee for specific implementation. At present, most designers combine the relevant simulation software provided by different BIM model software with Ecotec simulation software, then analyze the data of architectural design models in different stages according to the simulation software in BIM model software, and optimize the energy conservation and emission reduction scheme by using the analysis and design simulation results.

4.2. Enclosure Energy-Saving Design. The roof department of green building needs to be designed with comprehensive consideration of energy-saving factors. At present, the common roof shapes are mainly designed in the styles of high flat roof, slope flat roof, and various streamlined flat roofs. In terms of energy conservation and thermal performance design, it is usually necessary to consider the use of decorative materials, slope design, and thermal insulation layer to achieve good thermal insulation effects in summer and winter.

As the main part of the building, the goal of exterior wall energy conservation is to ensure the appropriate indoor temperature, avoid the impact of external high temperature, and reduce the adverse impact of indoor and outdoor temperature difference. The materials used for energy-saving exterior walls are usually composite building wall raw materials with good energy-saving effects, such as waterproof clay solid brick and centralized thermal insulation wall. As an important part of green buildings, windows are mainly used for ventilation, daylighting, and thermal insulation, which have a great impact on the energy consumption of the whole building to a certain extent. Therefore, the window design should not only meet the residential needs of users but also meet the requirements for building energy conservation.

The latest BIM design method can generally meet the needs of heat insulation and energy conservation of high-rise buildings and their auxiliary enclosure facilities. For example, using the BIM building model, different wall and roof building materials can be selected, and relevant parameters can be set to optimize the energy-saving construction scheme.

4.3. Sunshine Energy-Saving Design. How to design the sunshine conditions not only is the key to the energysaving design of green buildings but also can affect the daylighting effect in the building. Effective use of lighting energy-saving technology can reduce artificial energy consumption. In terms of natural lighting design, it is necessary to make full use of the reflected light generated by external sunlight to supplement indoor lighting, reduce the energy consumption required for indoor artificial lighting, and meet the lighting conditions required for building residence and life.

According to the national laws and policies on the green building industry, when using the Revit architecture model to simulate buildings, you can import the lighting software Ecotec to simulate and comprehensively analyze the indoor lighting, sunshine, and daylighting of buildings. According to the analysis results, you can adjust the structure of the building model or update relevant parameters for the redesign.

According to the technical standards for green building design, the average daylighting coefficient of bedrooms in buildings is related to sunshine conditions. Generally, the average daylighting coefficient of the bedroom is $4.7 \%$. The better the sunshine conditions, the greater the daylighting coefficient. The daylighting coefficient of indoor halls, kitchens, toilets, and other places is generally $1 \%[18,19]$. Due to the distance from the windows, it is generally difficult for these rooms to obtain a better sunshine environment. In the energy-saving design of green buildings, we should not only meet the standard of indoor daylighting coefficient but also meet the requirements of indoor energy conservation and environmental protection.

\section{Analysis Method of Building Energy Efficiency Based on BIM}

5.1. Characteristics of Building Energy Efficiency Analysis Based on BIM. In the past, there were many problems in building energy consumption analysis due to the limitation of technical conditions. The traditional building energy consumption analysis is mainly carried out in the construction process. The architectural design drawing cannot be changed, even if the problems found through energy consumption analysis cannot be reworked, resulting in a waste of human and material resources. Therefore, using the building model to analyze the energy consumption in the design stage and obtain the optimal design scheme can effectively improve the later construction efficiency and reduce the construction cost. The traditional energy consumption analysis method usually only analyzes a single factor without comprehensively considering the influence relationship between relevant factors, which makes this energy-saving scheme lack economy and practicability. For example, in the past, only the high-temperature performance of the building envelope was analyzed, or a single lighting 


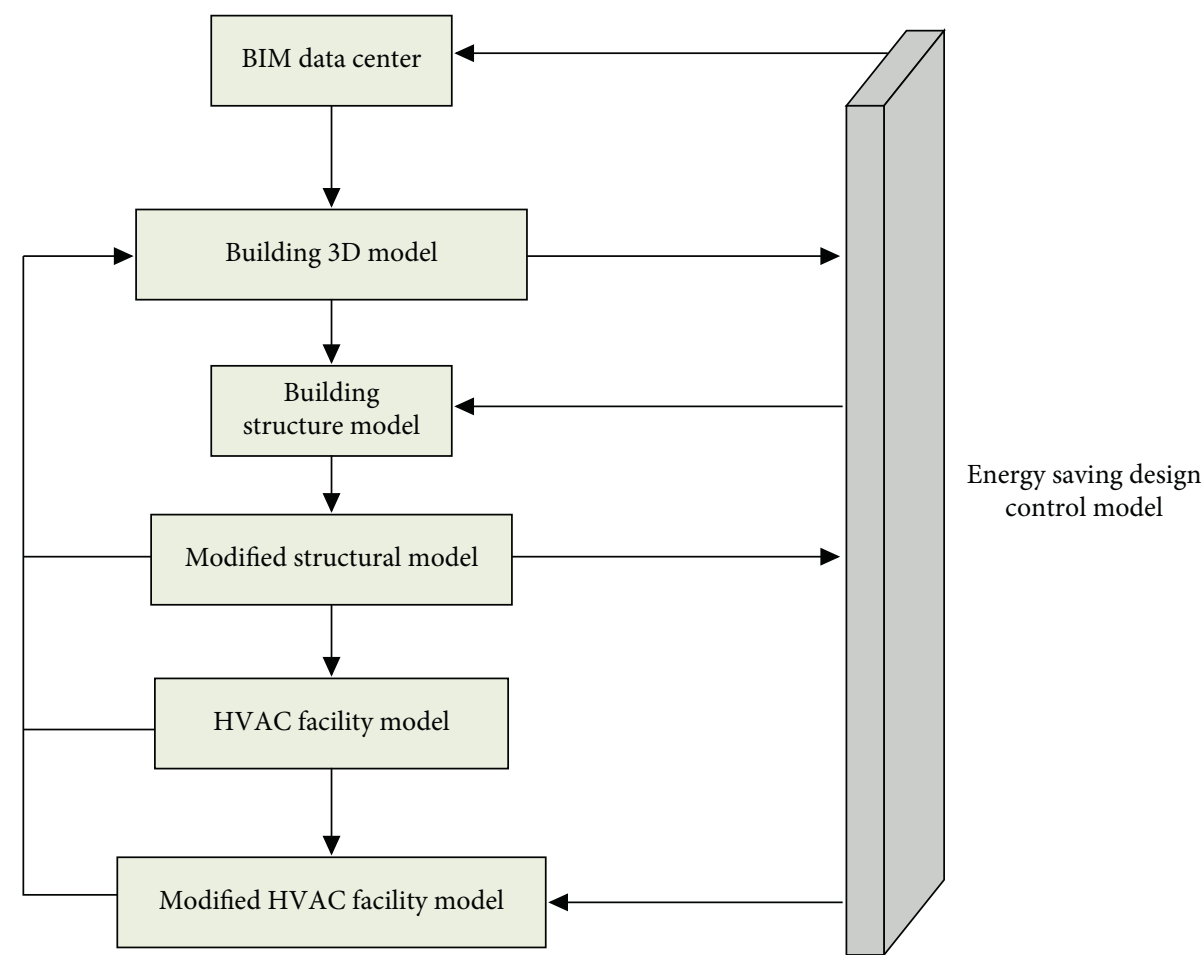

FIGURE 2: Information transmission process of green building energy efficiency design.

system and HVAC equipment were replaced to realize energy-saving transformation [20].

BIM technology is applied to process and analyze the data, the built building model is used to integrate and analyze the relevant information, external environment, and required parameters, and the building energy consumption is simulated and analyzed by running relevant programs. The building model based on BIM technology can realize the interaction between modeling software and energy consumption simulation software. Because building energy consumption involves the whole and part of the building and needs to be analyzed by using the knowledge of different professional fields, the interaction between different software must be used to help analysts continuously improve the modalism. Technology can realize the collaborative work between parametric modeling and energy consumption analysis, which is not only conducive to the scientific analysis and evaluation of energy-saving design effect but also conducive to the integration and sharing of information in the whole life cycle of the project so as to ensure the management to communicate and manage all departments below. In addition, through comprehensive energy consumption analysis, the building model based on BIM technology can not only analyze individual factors but also evaluate the overall performance of the building and the comprehensive effect of various factors. Thus, it can comprehensively grasp the situation of building energy consumption and provide decision support for various departments.

5.2. Building Energy Efficiency Analysis Process. In recent years, with the rapid development of BIM technology, it is more and more convenient to simulate and analyze building energy consumption, and the application of BIM energy consumption analysis software can comprehensively consider a variety of factors related to building projects in the construction process, such as building energy consumption and indoor energy consumption dynamic analysis. BIM energy consumption simulation software generally adopts Ecotec to design and analyze the energy consumption of specific building projects, and its main process is shown in Figure 3.

Usually, the first mock exam is required for different stages of construction projects. Because the design of a single model is mainly limited to a certain stage, in order to complete the whole construction project, the information of each stage must be integrated and processed. Among them, the interactive operation of each monomer model can not only effectively save the transmission time of information but also avoid various problems due to the required professional differences.

The building model based on BIM mainly contains the overall information of the construction project. Using BIM technology to simulate and analyze the energy consumption can not only export the effective information to the analysis software and complete the relevant analysis but also reduce the repeated work between different stages and improve the work efficiency.

Transfer the information contained in the BIM core building model to the relevant energy consumption analysis software, return the analysis results obtained by the energy consumption analysis software to the building model, and then continuously improve the energy-saving design effect by dynamically adjusting the model parameters. The specific information transfer process is shown in Figure 4. 


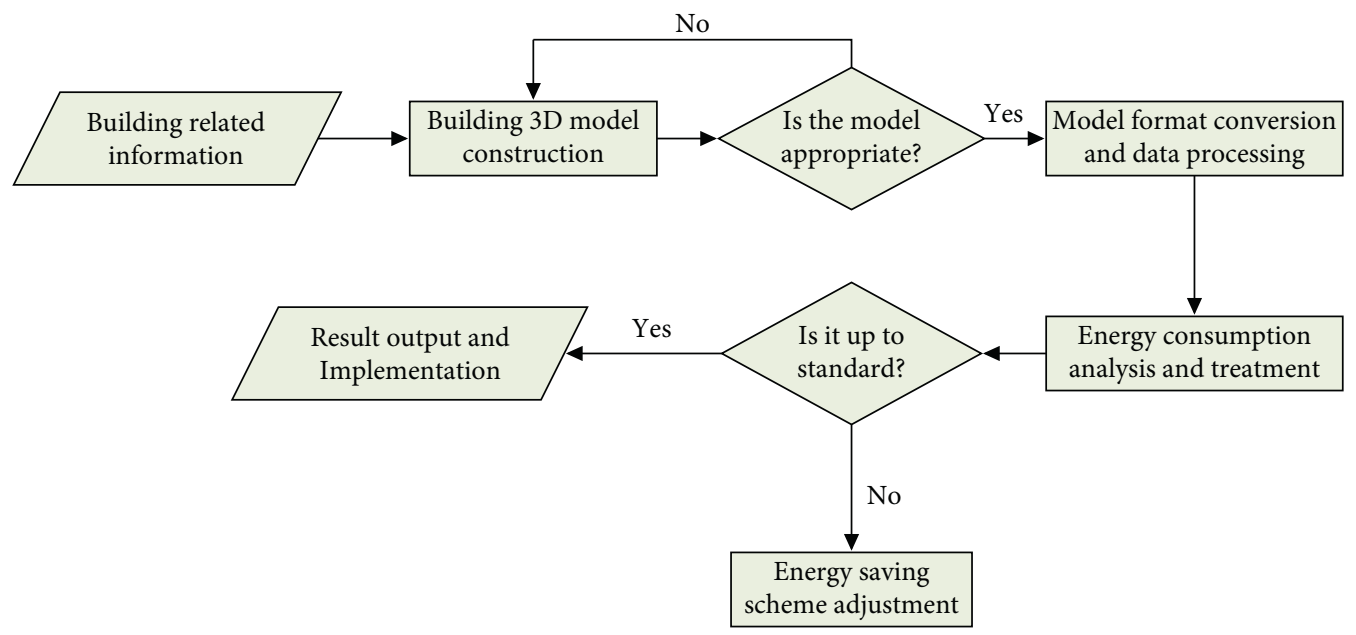

FIgURE 3: Energy consumption analysis method based on BIM.

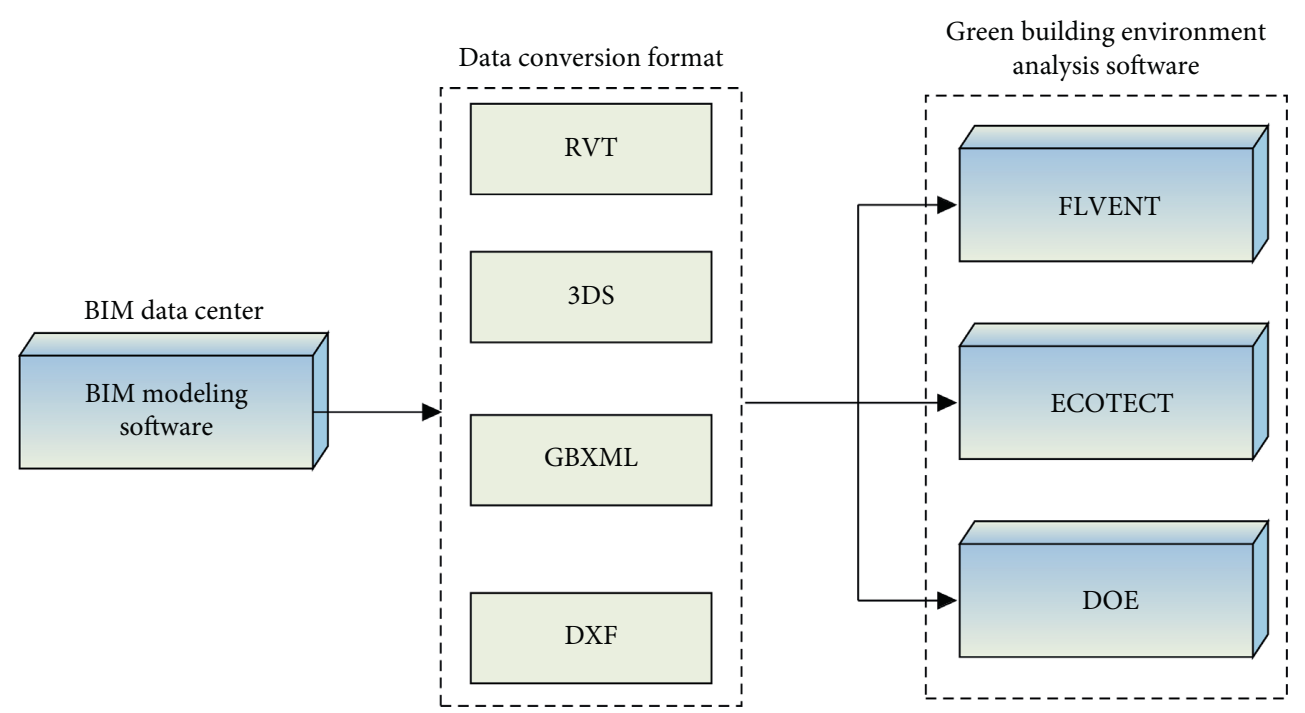

FIGURE 4: Interaction between BIM core software and building environment analysis software.

\section{Energy-Saving Effect Evaluation of Green Buildings Based on BIM}

6.1. Construction of Evaluation Index System. The energy consumption analysis software based on BIM technology mainly uses the building model in the design stage to simulate and analyze the energy-saving effect in the construction and use stages. Therefore, it is necessary to establish a relevant evaluation index system to evaluate the energy-saving effect of green buildings. The establishment of green building energy efficiency evaluation index is to promote construction project departments during the construction period; according to the local natural conditions, under the premise of ensuring the safety of the building, effectively improve energy utilization and reduce unnecessary losses caused by construction rework. The evaluation system should not only be the evaluation basis of building energy-saving effect but also provide guidance for guiding green building energy-saving design. Through the evaluation and analysis of the building energy efficiency effect of the evaluation system, the working process of each department of the construction project can be tracked, and the problems existing in the construction project can be summarized and analyzed.

Generally, a good evaluation system needs to follow certain principles. The first is to scientifically evaluate the energy-saving effect of green buildings through qualitative and quantitative analysis methods. Secondly, the evaluation indicators are adjustable and can be adjusted appropriately according to specific construction projects. In addition, it can simplify the index analysis and calculation process so that the evaluation process not only is easy to operate but also gives play to the practicability of the evaluation system.

Based on the evaluation standards of green building energy efficiency at home and abroad, the relevant reports output by green building energy consumption simulation analysis software can basically meet the standards of energysaving design. Therefore, the simulation results of energy consumption analysis software can be used as the basis for energy-saving effect evaluation. According to the different 
aspects involved in the energy-saving design of green buildings, the energy-saving evaluation index system of green buildings is established, as shown in Table 2 .

6.2. Evaluation Model of Energy-Saving Effect of Green Building. Using the established green building energy efficiency evaluation index system, comprehensively consider the different importance of indicators at all levels in the evaluation system, and calculate the weight value of corresponding indicators. The weight calculation method can consider the principles of subjectivity and objectivity.

According to the objectives, criteria, and specific design scheme of energy-saving design, the hierarchical structure model of the energy-saving effect evaluation index system can be established, as shown in Figure 5.

Based on the above energy-saving evaluation hierarchy model, in order to obtain the weight of each evaluation index, it is necessary to construct a relevant judgment matrix, as shown in the following equation:

$$
B=\left[\begin{array}{cccc}
b_{11} & b_{12} & \cdots & b_{1 m} \\
b_{21} & b_{22} & \cdots & b_{2 m} \\
\vdots & \vdots & \vdots & \vdots \\
b_{m 1} & b_{m 2} & \cdots & b_{m m}
\end{array}\right] .
$$

The numbers $1,2, \cdots, 10$ are usually used to represent the relative importance of each element in the judgment matrix. Then, according to the evaluation experts, the importance of each index is compared, and the corresponding scores are given to form a judgment matrix.

Then calculate the weight of each index. The specific calculation formula is as follows:

$$
\begin{aligned}
a_{i} & =\sqrt{\prod_{j=1}^{m} b_{i j},} \\
\overline{a_{i}} & =\frac{a_{i}}{\sum_{i=1}^{m} a_{i}}, \\
u & =\sum_{i=1}^{m} \frac{\sum_{j=1}^{m} b_{i j} \overline{a_{i}}}{m \overline{a_{i}}}(i=1,2, \cdots, m),
\end{aligned}
$$

where $\overline{a_{i}}$ represents each component value of the judgment matrix.

$$
\begin{aligned}
c & =\frac{u-m}{m-1}, \\
c q & =\frac{c}{q},
\end{aligned}
$$

where $c$ denotes the consistency index of judgment matrix, $q$ represents the random consistency index, and $c q$ means the revised consistency ratio.

The random consistency index values are shown in Table 3.
TABLE 2: Evaluation system of green building energy efficiency design effect and index relationship at all levels.

\begin{tabular}{ccc}
\hline Item & Primary index & Secondary index \\
\hline 1 & Energy-saving & Feasibility of design scheme \\
design & Quality of external protection \\
& & structure \\
& & Energy consumption \\
& & Lighting condition \\
2 & Energy consumption & Energy utilization \\
& & External environmental conditions \\
& & Indoor lighting condition \\
3 & condition & Light transmittance of external \\
& & window \\
4 & Ventilation & Indoor ventilation \\
& condition & Indoor air quality \\
& & Outdoor ventilation \\
\hline
\end{tabular}

When $c q<0.1$, it indicates that the judgment matrix has a good consistency. Otherwise, the consistency requirements can be achieved by continuously adjusting the element values of the judgment matrix.

After the establishment of an energy-saving evaluation index system, the qualitative indexes generally need to be treated quantitatively. Therefore, by setting the grade level of each evaluation index and then according to the different levels of these indexes in the evaluation index system or the importance of corresponding projects, they are divided into five grades: excellent, good, medium, qualified, and poor. The above five different grades can be represented by integers $10,9,8,7$, and 6 in turn.

The scores of each index are obtained by expert scoring, and the energy-saving effect evaluation sample matrix is established according to the scoring results. For example, suppose that the number of experts participating in the scoring is $z, x$ primary evaluation indicators are scored by experts in turn, and each primary evaluation indicator has $y$ secondary evaluation indicators; then the final energy-saving effect evaluation sample matrix can be expressed as

$$
S=\left[\begin{array}{cccc}
s_{111} & s_{112} & \cdots & s_{11 z} \\
s_{121} & s_{122} & \cdots & s_{12 z} \\
\vdots & \vdots & \vdots & \vdots \\
s_{x y 1} & s_{x y 2} & \cdots & s_{x y z}
\end{array}\right] .
$$

6.3. Application of Evaluation Model in Engineering Cases. According to the design technical scheme formulated by the Architectural Design Institute, a three-dimensional model of green building is created. Then, based on the BIM platform, different professionals and departments can work together. Figure 6 shows the three-dimensional building model, which includes the building structure model, and Figure 7 represents the electromechanical comprehensive models of building water supply and drainage system, HVAC facilities, and weak current made by different professionals.

Based on the BIM data platform and by importing the building model into the energy consumption analysis software, relevant analysis reports can be generated. 


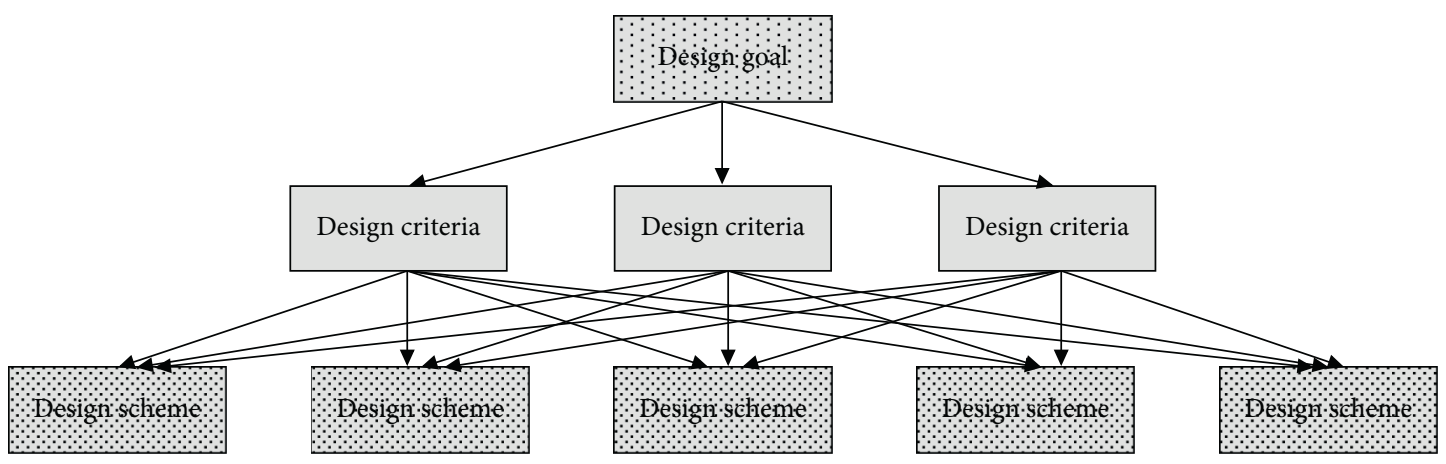

FIGURE 5: Energy-saving design evaluation hierarchy.

TABLE 3: Random consistency index values corresponding to different dimensions in the judgment matrix.

\begin{tabular}{lcccccccccc}
\hline Matrix dimension & 1 & 2 & 3 & 4 & 5 & 6 & 7 & 8 & 9 & 10 \\
\hline$Q$ & 0.01 & 0.02 & 0.36 & 0.54 & 0.82 & 1.15 & 1.27 & 1.32 & 1.41 & 1.49 \\
\hline
\end{tabular}

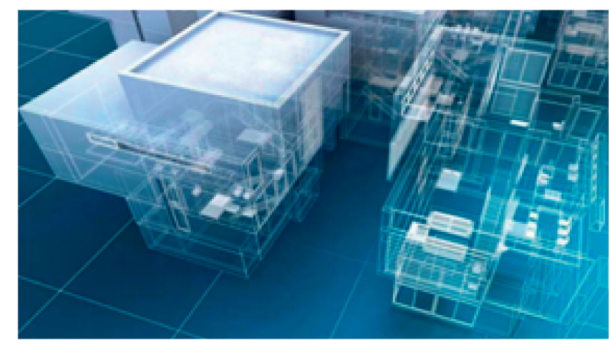

Figure 6: Three-dimensional building structure model.

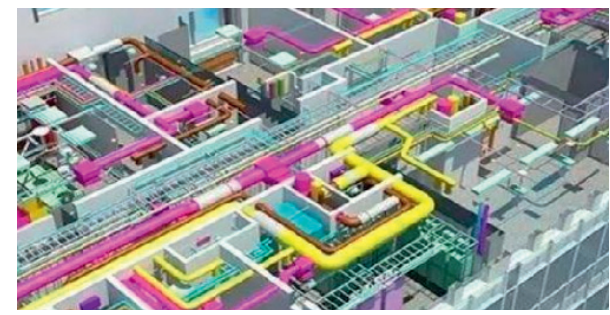

FIGURE 7: Electromechanical comprehensive model of building water supply and drainage system.

According to the analysis report and the evaluation index system of energy-saving effect of green buildings, the judgment matrix is constructed by using the primary index energy-saving design scheme $B_{1}$, energy consumption $B_{2}$, daylighting condition $B_{3}$, and ventilation condition $\mathrm{B}_{4}$. The primary index judgment matrix of energy-saving evaluation system is shown in Table 4.

$\bar{a}=(0.136,0.247,0.315,0.063)$ can be calculated from the judgment matrix. According to the consistency test formula, the maximum eigenvalue $u=4.13$ and $c q=0.014<0.1$. Through the consistency test, the weight values of each primary index are obtained, as shown in Table 5.

Then, each secondary index under each primary index can be compared in turn to determine the judgment matrix
Table 4: Primary index judgment matrix of energy-saving evaluation system.

\begin{tabular}{ccccc}
\hline $\mathrm{B}$ & $\mathrm{B}_{1}$ & $\mathrm{~B}_{2}$ & $\mathrm{~B}_{3}$ & $\mathrm{~B}_{4}$ \\
\hline $\mathrm{B}_{1}$ & 1 & 0.5 & 0.8 & 1.5 \\
$\mathrm{~B}_{2}$ & 1.5 & 1 & 2.5 & 3 \\
$\mathrm{~B}_{3}$ & 0.5 & 0.5 & 1 & 2.5 \\
$\mathrm{~B}_{4}$ & 0.8 & 0.5 & 1.5 & 1 \\
\hline
\end{tabular}

TABle 5: Primary index weight value of energy-saving evaluation index system.

\begin{tabular}{lc}
\hline Primary index & Weight value \\
\hline Energy-saving design & 0.136 \\
Energy consumption & 0.247 \\
Daylighting condition & 0.315 \\
Ventilation condition & 0.063 \\
\hline
\end{tabular}

of its layer. For example, by judging and comparing various factors under the primary index of energy-saving design, the corresponding judgment matrix is obtained, as shown in Table 6.

According to the judgment matrix, the corresponding $\bar{a}_{1}=(0.124,0.216,0.473)$ can be calculated. Through the consistency test, $c q=0.008<0.1$, meeting the requirements. After the consistency test, the weight values of each secondary index under the primary index are obtained, as shown in Table 7.

Similarly, the same method can be used to obtain the judgment matrix formed by comparing the elements under other primary indicators. At the same time, the corresponding weight can be obtained according to the judgment matrix. Finally, all different index weights of the green building energy-saving effect evaluation index layer can be calculated, as shown in Table 8.

Therefore, the corresponding scoring matrix can be constructed by using formula (4) and combined with the index weights at all levels of the energy-saving design effect evaluation system in Table 8. 
TABLE 6: Energy-saving evaluation index system secondary index judgment matrix.

\begin{tabular}{lccc}
\hline $\mathrm{B}_{1}$ & $\mathrm{~B}_{11}$ & $\mathrm{~B}_{12}$ & \\
\hline $\mathrm{B}_{11}$ & 1 & 0.8 & $\mathrm{~B}_{13}$ \\
$\mathrm{~B}_{12}$ & 2.5 & 1 & 0.6 \\
$\mathrm{~B}_{13}$ & 3 & 2 & 0.5 \\
\hline
\end{tabular}

TABLE 7: Secondary index weight value of energy-saving evaluation index system.

\begin{tabular}{lr}
\hline Secondary index & Weight value \\
\hline Feasibility of design scheme & 0.124 \\
Quality of external protection structure & 0.216 \\
Energy consumption & 0.473 \\
\hline
\end{tabular}

TABLe 8: Weight of indexes at all levels of energy-saving design effect evaluation system.

\begin{tabular}{lccc}
\hline Primary index & Weight value & Secondary index & Weight value \\
\hline & & Feasibility of design scheme & 0.124 \\
Energy-saving design & 0.136 & Quality of external protection structure & 0.216 \\
& & Energy consumption & 0.473 \\
& & Lighting condition & 0.103 \\
Energy consumption & 0.247 & Energy utilization & 0.185 \\
& & External environmental conditions & 0.327 \\
Daylighting condition & 0.315 & Indoor lighting condition & 0.162 \\
& & Light transmittance of external window & 0.538 \\
Ventilation condition & 0.063 & Indoor ventilation & 0.178 \\
& & Indoor air quality & 0.349 \\
& & Outdoor ventilation & \\
\hline
\end{tabular}

According to the grade classification of energy-saving effect evaluation of green buildings, it can be divided into five categories: excellent, good, medium, qualified, and poor, which is represented by integers $10,9,8,7$, and 6 . According to the energy-saving evaluation method proposed in this paper, the comprehensive evaluation result $M$ of energysaving effect of green buildings is calculated as follows:

$$
M=\left(\begin{array}{lllll}
0.21 & 0.17 & 0.35 & 0.23 & 0.13
\end{array}\right) \cdot\left(\begin{array}{c}
10 \\
9 \\
8 \\
7 \\
6
\end{array}\right) \text {. }
$$

The comprehensive evaluation value of the energysaving effect of the building project is 8.82 , which is between good and medium, indicating that the energy-saving effect of the green building model reaches the expected goal.

\section{Conclusion}

As an important development direction of the modern construction industry, green building was inseparable from the wide application of BIM technology. This paper made full use of BIM technology, which had the function of integrating building information model and its simulation. From the perspective of reducing building energy consumption and maintaining the sustainable development of the ecological environment, this paper studied the energysaving design method of green buildings based on BIM technology. This paper systematically expounded the design principles and design concepts of green buildings and gave the overall scheme of energy-saving design of green buildings. This paper deeply studied the energy-saving design elements of green buildings, which should be considered from the aspects of modeling software selection, envelope energy-saving design, and lighting energy-saving design and put forward the energy-saving analysis method of green buildings based on BIM. In addition, this paper also put forward the energy-saving effect evaluation method of green buildings based on BIM from the aspects of the design of energy-saving effect evaluation index system and the energy-saving effect evaluation model of green buildings. An example further verified that the energy-saving design method proposed in this paper had certain guiding significance for the field of green buildings [18]. The energy-saving design of green buildings based on BIM technology proposed in this paper can not only provide a reference for the in-depth research of BIM technology but also provide technical support for the wide application in the field of green buildings. 


\section{Data Availability}

The labeled dataset used to support the findings of this study is available from the corresponding author upon request.

\section{Conflicts of Interest}

The authors declare that there are no conflicts of interest.

\section{Acknowledgments}

This work was supported in part by the Project of Hebei University of Environmental Engineering: "The Research of Green Building Function Evaluation Based on BIM Technology" (no. 2020RWQN03).

\section{References}

[1] S. Azhar, "Building information modeling (BIM): trends, benefits, risks, and challenges for the AEC industry," Leadership and Management in Engineering, vol. 11, no. 3, pp. 241-252, 2011.

[2] J. Zhang, X. Hu, Z. Ning et al., "Energy-latency tradeoff for energy-aware offloading in mobile edge computing networks," IEEE Internet of Things Journal, vol. 5, no. 4, pp. 2633-2645, 2018.

[3] E. E. Sabelman and R. Lam, "The real-life dangers of augmented reality," IEEE Spectrum, vol. 52, no. 7, pp. 48-53, 2015.

[4] S. Azhar, W. A. Carlton, D. Olsen, and I. Ahmad, "Building information modeling for sustainable design and LEED rating analysis," Automation in Construction, vol. 20, no. 2, pp. 217-224, 2011.

[5] P. Bynum, R. R. A. Issa, and S. Olbina, "Building information modeling in support of sustainable design and construction," Journal of Construction Engineering and Management, vol. 139, no. 1, pp. 24-34, 2013.

[6] Z. Ma, S. Cai, N. Mao, Q. Yang, J. Feng, and P. Wang, "Construction quality management based on a collaborative system using BIM and indoor positioning," Automation in Construction, vol. 92, pp. 35-45, 2018.

[7] D. Castro-Lacouture, "Jorge A. Sefair, laura florez, andres L. Medaglia. Optimization model for the selection of materials using A leed-based green building rating system in," Colombia. Building and Environment, vol. 44, no. 6, pp. 156-167, 2009.

[8] A. T. Joel, C. Drury, and G. Susanne, "Comparative assessment of environmental performance tools and the role of the green builing challenge," Building Research \& Information, vol. 29, no. 5, pp. 324-335, 2010.

[9] H. Abdirad, "Metric-based BIM implementation assessment: a review of research and practice," Architectural Engineering and Design Management, vol. 13, pp. 52-78, 2017.

[10] Y. Deng, J. Li, Q. Wu, S. Pei, N. Xu, and G. Ni, "Using network theory to explore BIM application barriers for BIM sustainable development in China," Sustainability, vol. 12, no. 8 , p. $3190,2020$.

[11] W. He and B. Zhou, "Analysis of the status quo of green building operation management and countermeasures," IOP Conference Series: Earth and Environmental Science, vol. 632, no. 5, p. 52105, 2021.
[12] Z. Ning, X. Hu, Z. Chen et al., "A cooperative quality-aware service access system for social Internet of vehicles," IEEE Internet of Things Journal, vol. 5, no. 4, pp. 2506-2517, 2017.

[13] E. Seinre, J. Kurnitski, and H. Voll, "Building sustainability objective assessment in Estonian context and a comparative evaluation with LEED and BREEAM," Building and Environment, vol. 82, no. 82, pp. 110-120, 2014.

[14] J. Pinkse and M. Dommisse, "Overcoming barriers to sustainability: an explanation of residential builders' reluctance to adopt clean technologies," Business Strategy and the Environment, vol. 18, no. 8, pp. 515-527, 2010.

[15] C. Karkanias, S. N. Boemi, A. M. Papadopoulos, T. D. Tsoutsos, and A. Karagiannidis, "Energy efficiency in the Hellenic building sector: an assessment of the restrictions and perspectives of the market," Energy Policy, vol. 38, no. 6, pp. 2776-2784, 2010.

[16] U. Berardi, "Sustainable construction: green building design and delivery," Intelligent Buildings International, vol. 5, no. 1, pp. 65-66, 2013.

[17] D. Bryde, M. Broquetas, and J. M. Volm, "The project benefits of building information modelling (BIM)," International Journal of Project Management, vol. 31, no. 7, pp. 971-980, 2013.

[18] H. Abbasianjahromi, M. Ahangar, and F. Ghahremani, "A maturity assessment framework for applying BIM in consultant companies," Ijst-T Civ. Eng.vol. 431, pp. 637-649, 2019.

[19] Z. Ahmad, M. J. Thaheem, and A. Maqsoom, "Building information modeling as a risk transformer: an evolutionary insight into the project uncertainty," Automation in Construction, vol. 92, pp. 103-119, 2018.

[20] L. M. Khodeir, "Ashraf Ali Nessim. BIM2BEM integrated approach: examining status of the adoption of building information modelling and building energy models in Egyptian architectural firms," Ain Shams Eng, vol. 9, no. 4, pp. 1781-1790, 2018. 